\title{
A Comparison of the Surgical Outcomes of Laminoplasty and Laminectomy with Fusion in the Treatment of Multilevel Cervical Spondylotic Myelopathy: A Retrospective Cohort Study
}

\author{
Berk BENEK, Emrah AKCAY, Hakan YILMAZ, Murat AYDIN, Alaattin YURT \\ University of Health Sciences, Izmir Bozyaka Education and Research Hospital, Department of Neurosurgery, Izmir, Turkey \\ Corresponding author: Berk BENEK benekberk@gmail.com
}

\section{ABSTRACT}

AIM: To compare the effectiveness of laminoplasty and laminectomy with fusion in the treatment of patients with cervical spondylotic myelopathy (CSM).

MATERIAL and METHODS: This study retrospectively reviewed 52 patients diagnosed with CSM who underwent either laminoplasty (LP group) or laminectomy with fusion (LF group). The preoperative and postoperative clinical outcomes were evaluated using Cobb's angle of cervical lordosis, visual analogue scale (VAS) and modified Japanese Orthopaedic Association (mJOA) scores, and radiographs showing the antero-posterior diameter and area of the spinal canal.

RESULTS: The mean age of the LP group was 60.12 years, while that of the LF group was 63.84 years. The pre- and postoperative mean mJOA scores were $11.46 \pm 1.27$ and $15.27 \pm 0.87$, respectively, in the LP group and $10.15 \pm 1.89$ and $14.92 \pm 1.23$, respectively, in the LF group. The pre- and postoperative Cobb angles were $16.22 \pm 6.36^{\circ}$ and $14.45 \pm 4.50^{\circ}$, respectively, in the LP group and $14.39 \pm 5.34^{\circ}$ and $15.10 \pm 6.21^{\circ}$, respectively, in the LF group. Recovery rates were $58.26 \%$ and $60.76 \%$ in the LP and LF groups, respectively. The mJOA scores, antero-posterior diameter and area improved significantly after surgery in both groups, while the Cobb angle increased in the LF group and decreased in the LP group.

CONCLUSION: Laminoplasty and laminectomy with fusion improved neurological functions in patients diagnosed with CSM. Laminectomy with fusion should be the preferred choice when treating patients with preoperative axial pain as, despite expanding the spinal canal successfully, laminoplasty can also worsen the pain. However, laminectomy with fusion (except for OPLL) should not be the treatment of choice in a mobile spine as it severely restricts neck movements and impairs the Health-Related Quality of Life (HRQoL) of the patient. In the absence of kyphotic deformity, laminoplasty should be the preffered method for treatment.

KEYWORDS: Cervical spondylotic myelopathy, Laminoplasty, Laminectomy with fusion, Multilevel, Posterior technique

ABBREVIATIONS: CSM: Cervical spondylotic myelopathy, mJOA: Modified Japanese Orthopaedic Association, OPLL: Ossification of the posterior longitudinal ligament, LP: Laminoplasty, LF: Laminectomy with fusion, MRI: Magnetic resonance Imaging, CT: Computed tomography, SPSS: Statistical package for the social sciences, CCAI: C2-C7 Cobb angle improvement

Berk BENEK (1D: 0000-0002-4578-3681 Emrah AKCAY (D): 0000-0002-9666-0219 Hakan YILMAZ (1) : 0000-0002-2180-1195
Murat AYDIN (10): 0000-0001-6710-7695

Alaattin YURT (D) : 0000-0003-3621-0176 


\section{INTRODUCTION}

$\longrightarrow$ ervical spondylotic myelopathy (CSM) is a progressive, degenerative disease that causes compression of the spinal cord and triggers neurological dysfunction in patients (7). CSM is often associated with ossification of the posterior longitudinal ligament (OPLL) and ligamentum flavum, spondylolisthesis, compressional changes in the spinal cord, and degenerative disc disease $(13,23)$. Additionally, compression of the spinal cord and vasculature may lead to myelopathic symptoms which are known to be correlated with the area and diameter of the spinal cord $(17,14)$.

Surgical intervention may help prevent further deterioration of neurological functions $(1,24)$, and posterior cervical surgeries such as laminoplasty (LP) or laminectomy with fusion (LF) are generally preferred in patients with multilevel ( $\geq 3$ segments) cervical involvement as they are known to be effective and reliable treatment methods. The surgical procedure should be chosen after preoperative evaluation of the cervical lordosis angulation, with laminoplasty recommended in preserved lordotic patients and laminectomy with fusion preferred in flexible kyphotic patients, those exhibiting instability, and those experiencing moderate to high preoperative axial neck pain. However, currently there is a lack of a standardized method of selection, and the aim of this study was to assess and compare the effectiveness of these two surgical procedures in order to address this gap.

\section{MATERIAL and METHODS}

This study retrospectively reviewed the data of 52 patients diagnosed with multilevel CSM involving C3-6 who underwent posterior cervical surgery, specifically laminoplasty or laminectomy with fusion, at the Department of Neurosurgery, University of Health Sciences Izmir Bozyaka Education and Research Hospital between January 2013 and May 2019. Posterior surgery was preferred in patients with spinal stenosis, spinal cord compression, and symptoms of myelopathy, and those diagnosed with fixed kyphosis were excluded from this study as posterior intervention for this indication was not performed in our department. Additionally, patients with cervical instability or cervical kyphosis with negative modified $\mathrm{K}$-line were also not recommended for laminoplasty procedure.

The patients were divided into two groups, as follows: a) LP: those who underwent open door laminoplasty $(n=26$; Figures 1A-J, 2A-J, 3A-H), and b) LF: those who underwent laminectomy with fusion ( $n=26$; Figure $4 A-J, 5 A-J, 6 A-N)$. All patients were mobilized on the first postoperative day, and were made to use a cervical collar for four weeks thereafter. Clinical outcomes prior to surgery and at the final follow-up appointment were evaluated using the modified Japanese Orthopaedic Association (mJOA) scale, and the recovery rate, calculated based on the formula (Recovery rate(\%) = [Postoperative score - preoperative score] / [Full score(18) preoperative score] $\mathrm{x100}$ ) suggested by Hirabayashi et al., was used to evaluate success of the surgical procedure (9). A recovery rate of $<25 \%$ was considered as poor, $25-50 \%$ as insufficient, $50-75 \%$ as good, and $>75 \%$ as excellent. Pain
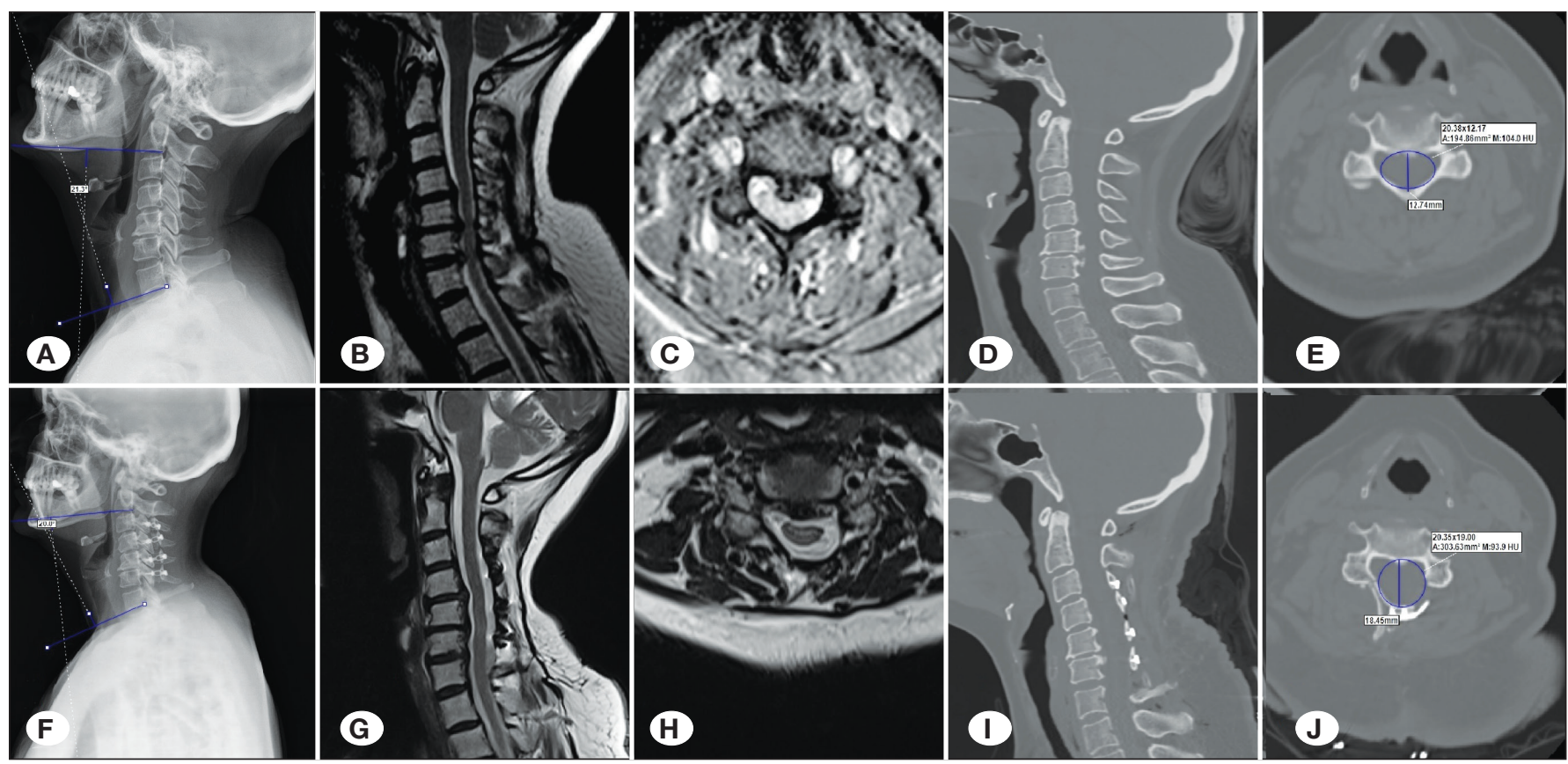

Figure 1: A) Preoperative lateral cervical radiograph showing $\mathrm{C}_{2}-\mathrm{C}_{7}$ Cobb angle; preoperative T2W sagittal (B) and axial (C) MRIs showing spinal cord compression; preoperative sagittal (D) and axial (E) CT scans showing spinal cord compression; E) preoperative axial CT scan at $\mathrm{C}_{4-5}$ level showing measurement of the antero-posterior diameter and canal area; F) postoperative C2-C7 Cobb angle in lateral cervical radiogram; postoperative sagittal (I) and axial (J) CT scans after C3- C6 open door laminoplasty showing apparent widening of the spinal canal; postoperative sagittal (G) and axial (H) MRI scans after C3- C6 open door laminoplasty showing apparent widening of the spinal canal. 


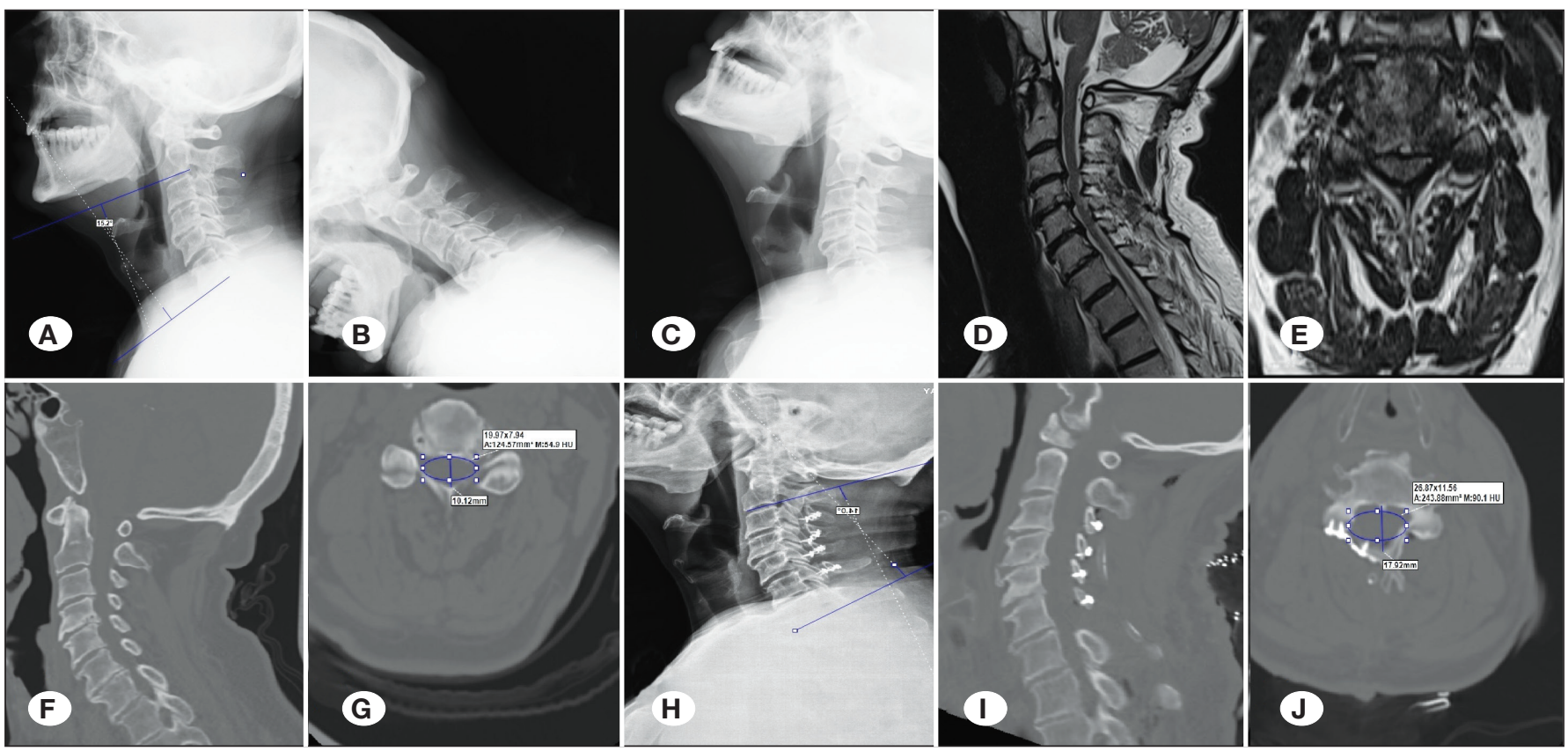

Figure 2: Preoperative lateral radiographs in neutral (A), flexion (B), and extension (C) of the cervical spine showing lordotic curvature without instability. Preoperative sagittal (D) and axial (E) MRIs and CT sagittal (F) and axial (G) images of the cervical spine showing the diameter and area. Postoperative CT images (H: lateral radiogram, I: sagittal CT scan, J: axial CT scan) showing the expansion of the dural sac (C3 to $\mathrm{C} 6)$ on the side of the laminoplasty.
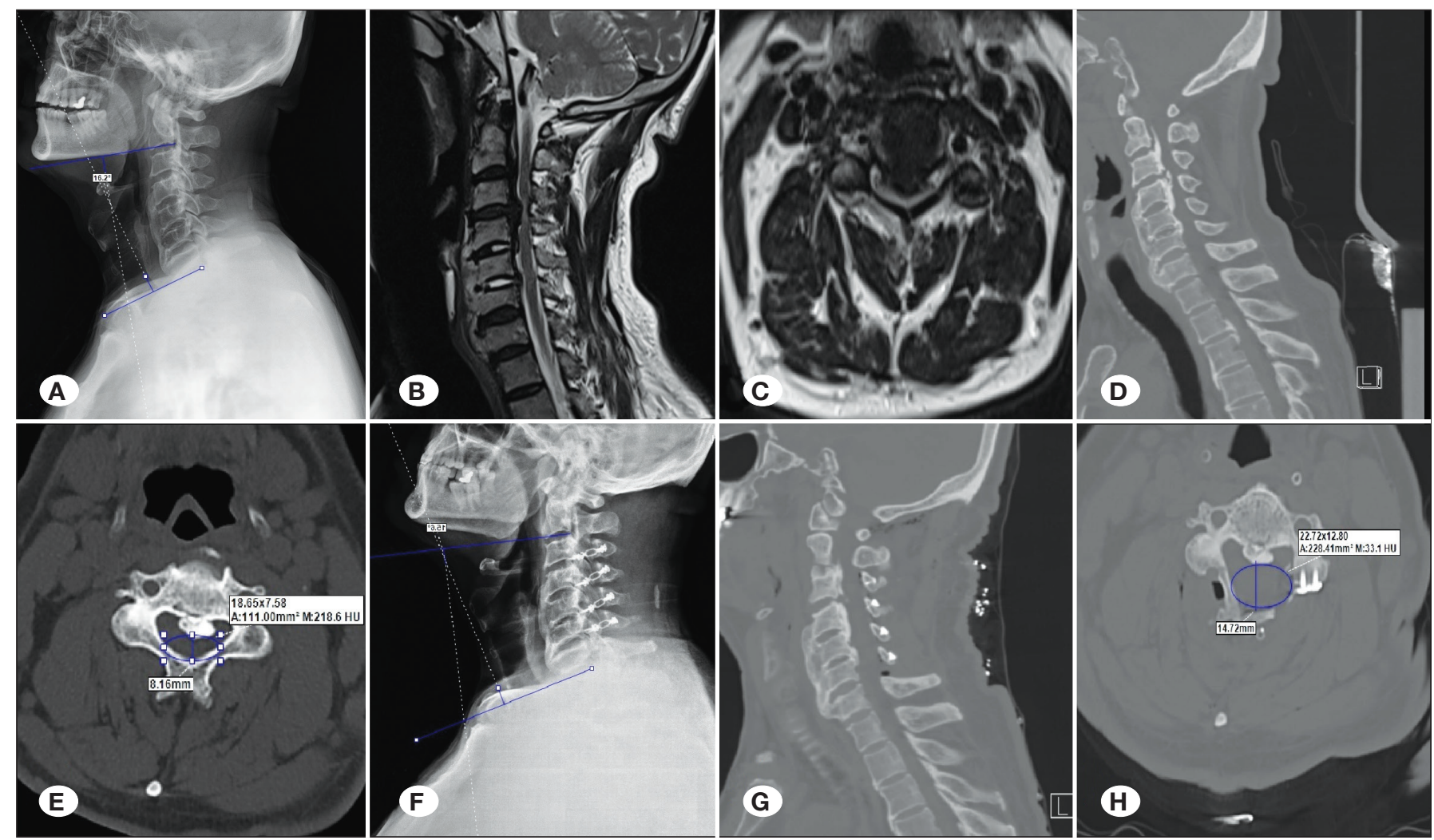

Figure 3: Laminoplasty for cervical spondylotic myelopathy at C3-C6 with OPLL. Preoperative lateral radiograph (A), MRI (B: sagittal, C: axial), and CT (D: sagittal, E: axial) showing degeneration of the cervical spine. Postoperative direct radiograph (F) and CT (G: sagittal, H: axial) after multilevel laminoplasty was performed. 
was assessed using the visual analog scale (VAS), ranging from 0 (no pain) to 10 (severe pain).

Cervical radiography, dynamic flexion-extension lateral radiography, cervical $\mathrm{CT}$, and cervical MRI examinations were carried out before and after surgery. The anterior-posterior diameter and area of the spinal canal at C4-C5 levels were measured using axial CT scans, while the Cobb angle of cervical lordosis was evaluated using the lateral cervical radiograph (Figures 1,2,3,4,5,6). Occurrence of complications such as axial pain and C5 palsy were recorded in both groups, and the mean follow-up period was 20 months (range: 12 to 30 months). Written informed consent was collected from all patients, and this study was approved by the institutional ethics review committee at the University of Health Sciences
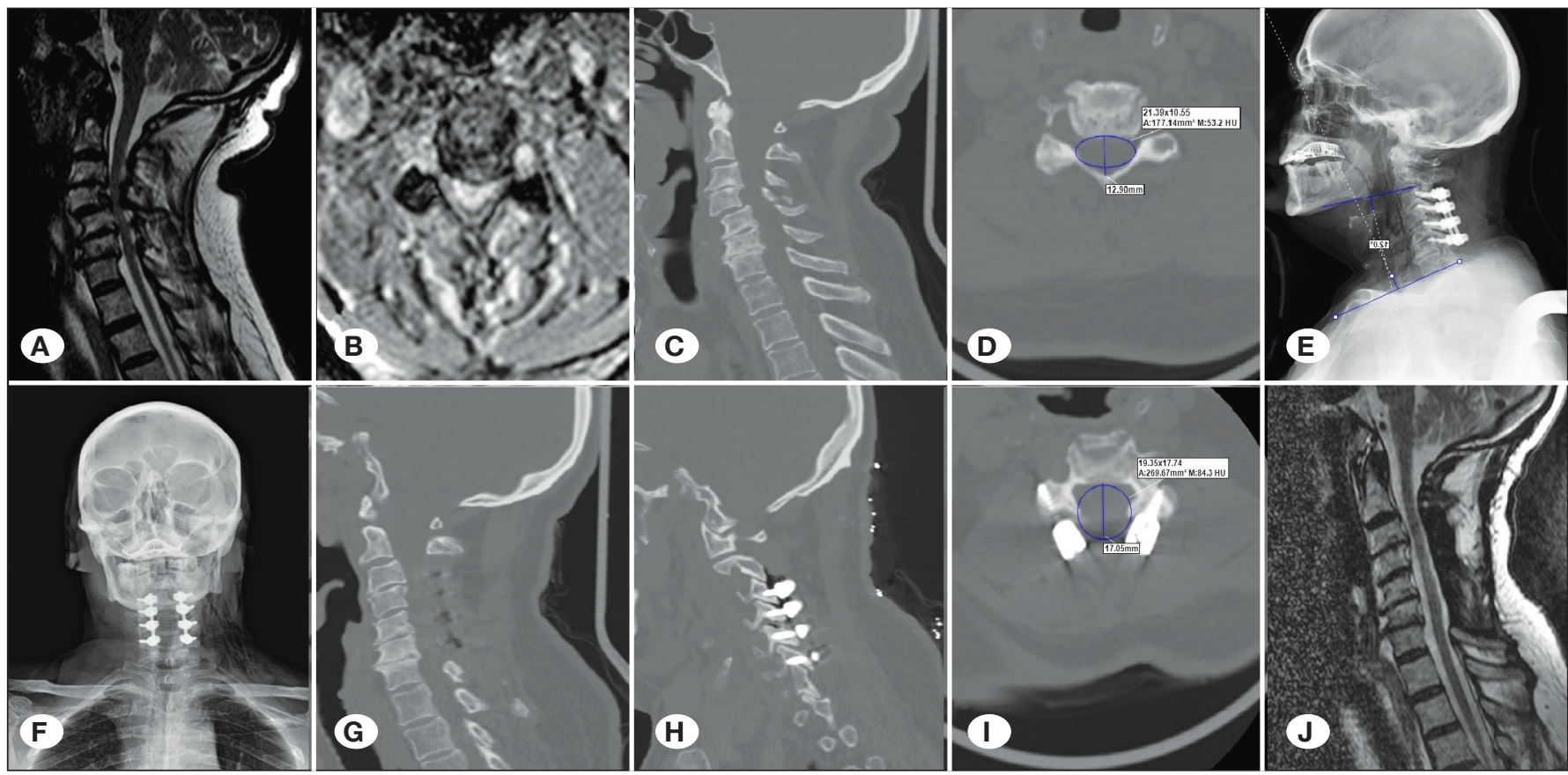

Figure 4: Preoperative T2W MRI (A: sagittal, B: axial), and CT scan (C: sagittal, D: axial) of cervical spondylotic myelopathy with cervical instability. Postoperative radiograph (E: lateral, F: anteroposterior), CT scan (G, H: sagittal, I: axial), and (J) sagittal MRI after C3-C6 laminectomy with placement of lateral mass screws showing expansion of the canal and restoration of cervical alignment.

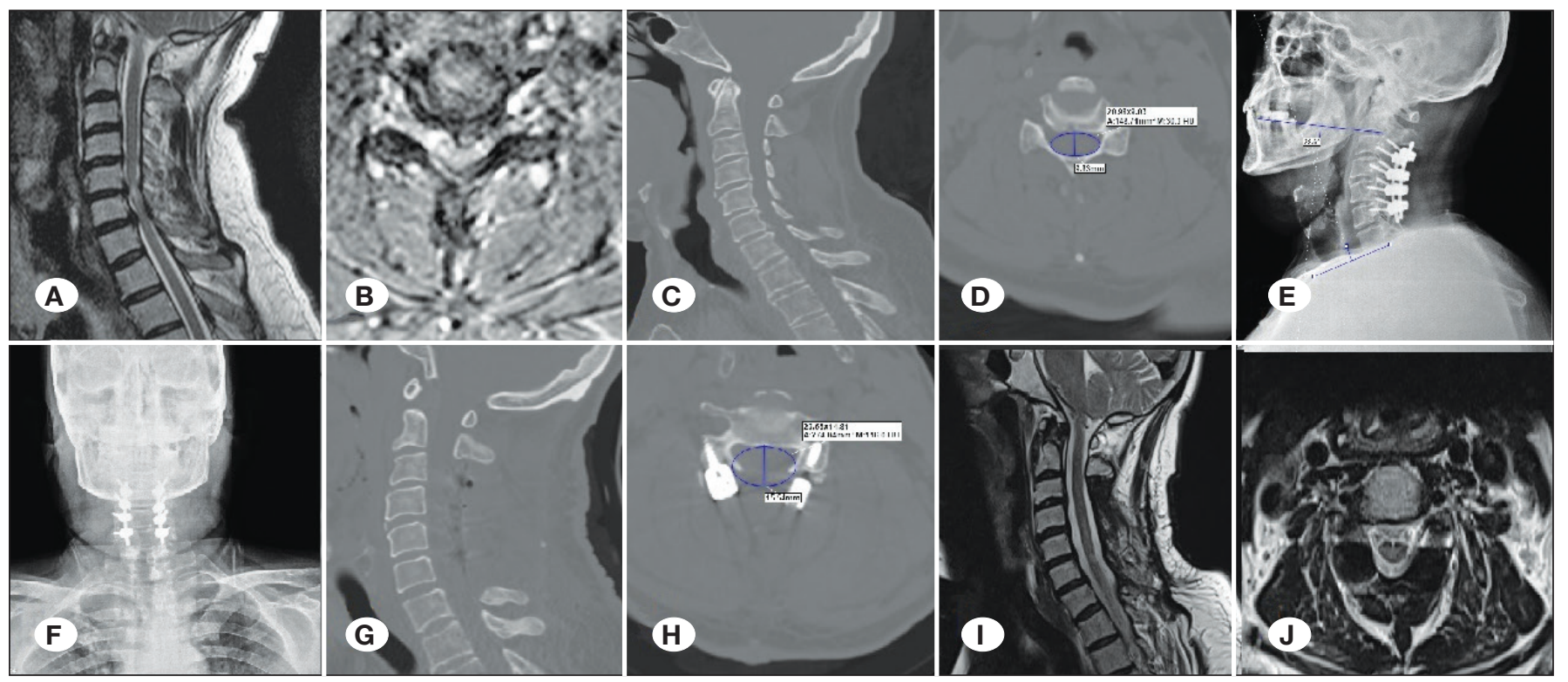

Figure 5: Preoperative snake eye apperence and narrowing of spinal canal in T2W MRI (A: sagittal, B: axial) and CT (C: sagittal, D: axial) images. Postoperative direct radiograph (E: lateral, F: anteroposterior), CT (G: sagittal, H: axial), and T2W MRI (I: sagittal, J: axial) showing enlargement of the canal. 


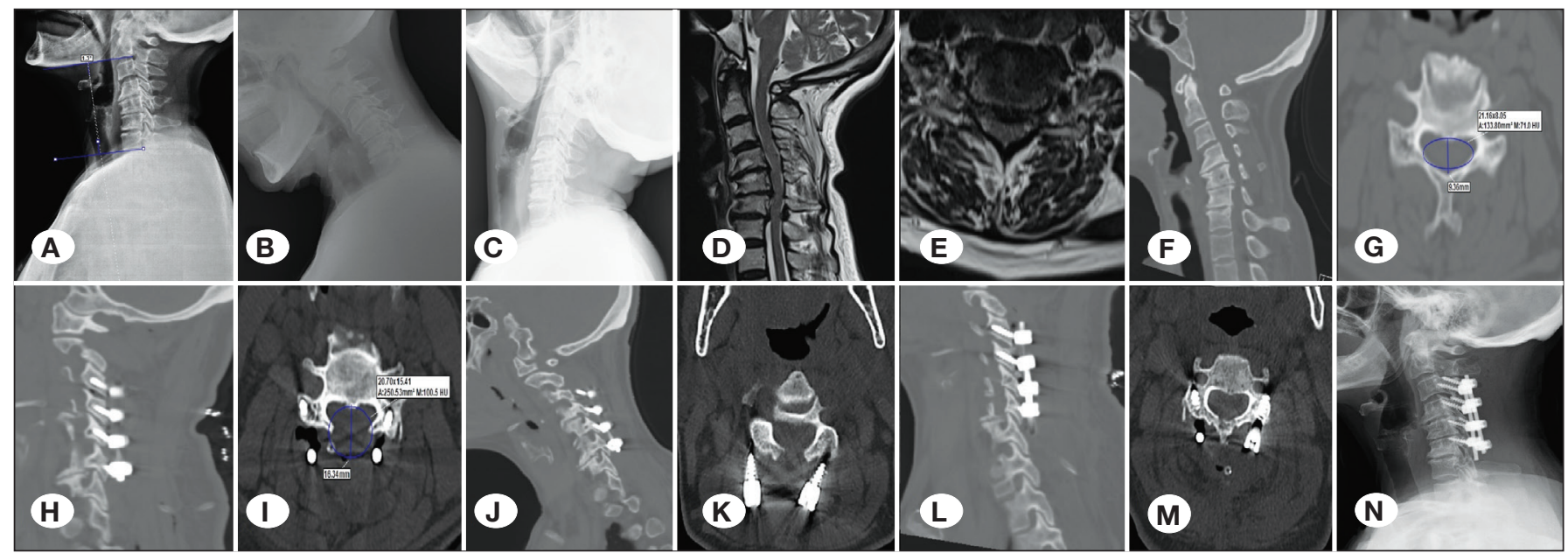

Figure 6: Preoperative lateral cervical radiographs in neutral (A), flexion (B), and extension (C) with flexible kyphosis. Preoperative MRI (D: sagittal, E: axial), and CT (F: sagittal, G: axial) of CSM with severe narrowing. CT images (H: sagittal, I: axial) after laminectomy with fusion showing the inserted screws and canal expansion. The patient had a traffic accident with flexion injury two months after the first operation (J: sagittal, K: axial) and was reoperated on in order to pull out the upper screws (L: sagittal, M: axial CT scans, N: lateral $\mathrm{x}$-ray).

Izmir Bozyaka Education and Research Hospital (Date: 12.05.2020, Issue No: 15345988) in accordance with the World Medical Association Declaration of Helsinki and its most recent amendments.

\section{Surgical Procedure}

All surgeries included in this study were conducted by the same experienced surgeons at our hospital. All patients were positioned horizontally and fixed with slight flexion under general anesthesia. A midline cervical skin incision was made and the paravertebral muscles were detached bilaterally from the spinous processes to expose the laminae and lateral masses. The cervical level was confirmed using fluoroscopy, and all included procedures were performed within 4 levels ranging from $\mathrm{C} 3$ to $\mathrm{C} 6$. The interspinous ligaments were cut at the superior and inferior ends of the target levels, and the supraspinal ligaments were retained. In the LP group, automated high-speed burrs were used to drill a full-thickness gutter at the junction of the articular process and the laminae on the dominant side of the symptoms and a partial-thickness gutter on the contralateral hinge side. The laminae were then elevated from the open side towards the hinge side as a greenstick fracture, and a mini-plate was placed in each of the four levels to maintain the open lamina. C7 arcocristectomy was performed in 6 patients. In the LF group, total laminectomy and flavectomy were performed just medial to the pedicles at four levels (C3-C4-C5-C6), and polyaxial screw-rods were inserted through the lateral masses bilaterally using the Magerl technique to stabilize the cervical spine. The screw locations were checked using $\mathrm{C}$-arm fluoroscopy during surgery.

\section{Statistical Analyses}

All statistical analyses were performed using the Statistical Package for Social Sciences (SPSS) software, version 20. The Mann-Whitney U-test was used to compare the two independent groups, while the pre- and postoperative dependent variables (mJOA, Cobb, diameter, and area) were compared using the Wilcoxon signed-rank test. A p-value $\leq 0.05$ was considered to be statistically significant.

\section{RESULTS}

This study included 52 patients diagnosed with multilevel cervical spondylotic myelopathy who underwent laminoplasty or laminectomy with fusion. Of these, 41 patients were male $(79 \%)$ and 11 were female $(21 \%)$, resulting in a male:female ratio of $3.73: 1$, and the mean age of the study cohort was 61.98 years (range: $36-75$ years). The LP group (mean age: 60.12 years; range: $36-73$ years) consisted of 21 males and 5 females, while the LF group (mean age: 63.84; range: 42-75 years) was made up of 20 males and 6 females (Table I). The difference in distribution of gender between the two groups was not statistically significant ( $p>0.05)$.

\section{Clinical Evaluation}

The mJOA scores significantly improved in both groups $(p<0.05)$, with the mean preoperative and postoperative scores being $11.46 \pm 1.27$ and $15.27 \pm 0.87$, repectively, in the LP group and $10.15 \pm 1.89$ and $14.92 \pm 1.23$, respectively, in the LF group. The recovery rates were $58.26 \%$ and $60.76 \%$ in the LP and LF groups respectively, although this difference was not statistically significant ( $p>0.05$; Table II). The VAS scores were $4.8 \pm 2.2$ preoperatively and $2.2 \pm 1.2$ two months postoperatively in the LP group, while the corresponding scores in the LF group were $7.1 \pm 2.6$ and $1.6 \pm 0.8$, respectively. Early postoperative axial neck pain was observed in the majority of patients who underwent laminoplasty, although the pain was seen to subside within one month.

\section{Radiographic Evaluation}

Apparent widening of the spinal canal diameter was confirmed postoperatively. The mean anterio-posterior diameter of the spinal canal at C4-C5 increased from $10.57 \pm 1.59 \mathrm{~mm}$ 
Benek B. et al: Laminoplasty and Laminectomy with Fusion

Table I: Demographic Characteristics of the Patients Who Underwent Laminoplasty and Laminectomy with Fusion

\begin{tabular}{lcc}
\hline & Laminoplasty (LP Group) & Laminectomy with Fusion (LF Group) \\
\hline Number & 26 & 26 \\
\hline $\begin{array}{l}\text { Gender } \\
\text { Number of males/ females }\end{array}$ & $21 \mathrm{M} / 5 \mathrm{~F}$ & $20 \mathrm{M} / 6 \mathrm{~F}$ \\
\hline Average age at operation (years) & 60.12 (range 36-73) & 63.84 (range 42-75) \\
\hline
\end{tabular}

M: male, F: female.

Table II: Comparison of Pre-and Postoperative Results of Laminoplasty and Laminectomy with Fusion Groups in the Treatment of Multilevel CSM

\begin{tabular}{|c|c|c|}
\hline & $\begin{array}{l}\text { Laminoplasty } \\
\text { (LP Group) }\end{array}$ & $\begin{array}{l}\text { Laminectomy with } \\
\text { Fusion (LF Group) }\end{array}$ \\
\hline \multicolumn{3}{|l|}{ mJOA score } \\
\hline Preoperative & $11.46 \pm 1.27$ & $10.15 \pm 1.89$ \\
\hline Postoperative & $15.27 \pm 0.87$ & $14.92 \pm 1.23$ \\
\hline p-value & $<0.0001$ & $<0.0001$ \\
\hline Recovery rate & $58.26 \%$ & $60.76 \%$ \\
\hline \multicolumn{3}{|l|}{$\mathrm{C}_{2-} \mathrm{C}_{7}$ Cobb angle $\left({ }^{\circ}\right)$} \\
\hline Preoperative & $16.22 \pm 6.36^{\circ}$ & $14.39 \pm 5.34^{\circ}$ \\
\hline Postoperative & $14.45 \pm 4.50^{\circ}$ & $15.10 \pm 6.21^{\circ}$ \\
\hline $\mathrm{p}$-value & 0.045 & 0.309 \\
\hline CCAI & -1.77 & +0.71 \\
\hline \multicolumn{3}{|l|}{ Diameter (mm) } \\
\hline Preoperative & $10.57 \pm 1.59$ & $10.59 \pm 0.95$ \\
\hline Postoperative & $16.44 \pm 1.52$ & $16.38 \pm 1.15$ \\
\hline $\mathrm{p}$-value & $<0.0001$ & $<0.0001$ \\
\hline \multicolumn{3}{|l|}{ Area $\left(\mathrm{mm}^{2}\right)$} \\
\hline Preoperative & $156.19 \pm 32.93$ & $147.42 \pm 11.29$ \\
\hline Postoperative & $273.59 \pm 50.32$ & $266.08 \pm 27.01$ \\
\hline p-value & $<0.0001$ & $<0.0001$ \\
\hline
\end{tabular}

Data are expressed as mean \pm SD. LP: laminoplasty; LF: Laminectomy with fusion, CCAl: C2-C7 Cobb angle improvement. $p$-value $\leq 0.05$ was considered statistically significant.

preoperatively to $16.44 \pm 1.52 \mathrm{~mm}$ postoperatively in the LP group, and from $10.59 \pm 0.95 \mathrm{~mm}$ to $16.36 \pm 1.15 \mathrm{~mm}$ in the LF group. This increase was statistically significant $(p<0.05)$ in both groups, although the preoperative anterio-posterior diameter did not differ significantly between the two groups (p>0.05) (Table II).

The mean preoperative and postoperative spinal canal areas at C4-C5 were $156.19 \pm 32.93 \mathrm{~mm}^{2}$ and $273.54 \pm 50.32$ $\mathrm{mm}^{2}$, respectively, in the LP group and $147.42 \pm 11.29 \mathrm{~mm}^{2}$ and $266.08 \pm 27.01 \mathrm{~mm}^{2}$, respectively, in the LF group. This increase was statistically significant in both groups $(p<0.05)$, although the preoperative spinal canal area did not differ significantly between the two groups (Table II).

The preoperative and postoperative Cobb angles at $\mathrm{C} 2-\mathrm{C} 7$ were $16.22 \pm 6.36^{\circ}$ and $14.45 \pm 4.50^{\circ}$, respectively, in the LP group and $14.39 \pm 5.34^{\circ}$ and $15.10 \pm 6.21^{\circ}$, respectively, in the LF group. Therefore, the C2-C7 Cobb angles increased in the LF group, but decreased in the LP group ( $p$-value: 0.045). The sagittal alignment did not change significantly after surgery in the LF group ( $p>0.05)$. However, a significant difference in the $\mathrm{C} 2-\mathrm{C} 7 \mathrm{Cobb}$ angle improvement (CCAl) was observed between the two groups $(p<0.05)$ (Table II).

Postoperative complications included axial pain in seven cases, transient C5 palsy in three cases, and cerebrospinal fluid leakage in two cases. One patient who underwent laminectomy with fusion had a traffic accident with flexion injury two months after the first surgery, requiring re-operation to pull out the upper screws (Figure 6A-N). C5 palsy was observed in one patient who underwent laminoplasty and two patients who underwent laminectomy with fusion. However, no permanent complications associated with the surgical techniques were seen to occur. Axial pain symptoms were relieved using non-steroidal anti-inflammatory drugs, and patients exhibiting C5 palsy recovered fully within three months after the operation. Cerebrospinal fluid leakage was treated using bed-rest for three weeks.

\section{DISCUSSION}

Posterior cervical surgery is the preferred treatment of choice for multilevel (involving more than three levels) cervical spondylotic myelopathy as it aims to decompress the spinal cord, restore sagittal alignment, and stabilize the spine (12). Factors that affect the treatment plan include sagittal curvature, location of the compressive pathology, and the number of levels involved (5). Laminoplasty and laminectomy with fusion have both been recognised as reliable, effective, and popular posterior surgical procedures that can provide extensive decompression of segments easily (3). However, as the ideal treatment of choice for multilevel CSM is still controversial, the aim of this study was to compare the surgical outcomes of laminoplasty and laminectomy with fusion in the treatment of cervical spondylotic myelopathy involving 4 levels (C3-C6).

Hirabayashi et al. first described unilateral open-door laminoplasty in 1981 (9), and many modified versions of this procedure, including the open door and French door techniques, have been developed since. In the open door technique, the 
opening is made at the lateral mass-laminar junction such that the hinge is unilateral, while the French door method is performed along the midline such that the hinge is bilateral (18). Laminoplasty has the advantage of maintaining laminar integrity as it expands the cervical canal while protecting the posterior elements of the spine and maintaining stability (24). Occassionally, arcocristectomy, where only the upper half of the cervical laminae of $\mathrm{C} 7$ and ligamentum flavum are removed to enlarge the spinal canal, may be performed in addition to laminoplasty in order to prevent kyphotic deformity by preserving the supraspinosus and interspinosus ligaments and muscle attachments to the $\mathrm{C} 7$ spinosus process (22). On the other hand, laminectomy with fusion, where the polyaxial screws are inserted through the lateral masses using various techniques, may be performed to stabilize the cervical spine and prevent kyphosis after laminectomy. Ideal candidates for this procedure include patients with multilevel CSM exhibiting preserved cervical lordosis, flexible kyphosis, or cervical instability (12).

A diagnosis of absolute spinal canal stenosis may be made when the anteroposterior diameter of the cervical spine is $12 \mathrm{~mm}$ or less, while diameters between 12 to $14 \mathrm{~mm}$ may be characterized as relative spinal canal stenosis. A canal diameter of $12 \mathrm{~mm}$ or lower may be considered as the lower limit value for a diagnosis of myelopathy (24). The Pincer effect may be defined as a phenomenon where movement of adjacent vertebrae during extension results in a decrease in the spinal canal diameter. In the current study, both groups exhibited similar preoperative baseline measures including the mJOA score, C2-7 Cobb angle, antero-posterior cervical canal diameter, and spinal canal area (Table I).

Several studies have previously compared the outcomes of posterior surgical procedures for the treatment of multilevel CSM. The three key clinical variables to consider when developing a treatment plan for CSM are age, duration of symptoms, and severity of myelopathy at presentation, while the factors affecting prognosis and surgical outcomes age, preoperative JOA score, and preoperative increased signal intensity (ISI) on T2W-MR (20). In case of multilevel compression involving three or more levels, presence of significant kyphosis plays an important role in choosing between laminoplasty or laminectomy and fusion (24). The sagittal alignment of the cervical spine has also been shown to play a significant role in predicting the outcomes of CSM (15), with patients exhibiting poorer outcomes if the curvature is kyphotic. Moreover, Lee et al. reported that patients with straight lordosis may develop kyphosis after laminoplasty, and the C2-C7 Cobb angle was seen to increase in the LF group but decrease in the LP group in the current study (Table II) (11). Preservation of the C7-T1 supraspinal ligaments and partial interspinous ligaments after LP may play an important role in preventing cervical kyphosis (4), and a biomechanical study previously showed that resection of the C7-T1 intraspinous and supraspinous ligaments after LP could lead to a large increase in C7-T1 segmental motion (8). As a result, laminectomy with fusion and placement of lateral mass screws was considered superior to laminoplasty when reconstructing cervical lordosis (Table II), and the latter should ideally be avoided in kyphotic patients (5). In the current study, the patients in both groups were selected using the same inclusion criteria, that is, C3C6 compression of the spinal cord and no evidence of fixed cervical kyphosis, in order to enhance comparability. All patients with obvious cervical kyphosis or with negative kyphosis lines (K-line) were excluded.

In the current study, neurological function was evaluated using the mJOA score, and a significant improvement was observed post-surgically in both groups. Moreover, the mJOA neurological function recovery rates were similar between the two groups. Therefore, both techniques were considered effective as they successfully expanded the spinal canals adequately. Posterior laminectomy with fusion may be preferred in case of moderate to high preoperative axial neck pain or evidence of instability, measured using neutral or flexion-extension lateral radiograms (12).

The most frequent post-surgical complications associated with posterior cervical surgery for CSM are C5 palsy and axial neck pain, especially after laminoplasty. However, careful selection of patients ensuring low preoperative axial pain and appropriate cervical curvature can ensure that laminoplasty does not worsen the pain (19). In the current study, four patients in the LP group and three patients in the LF group developed posterior axial pain. Chiba et al. previously reported that axial pain was seen to persist up to 14 years postsurgically in $28 \%$ of the patients undergoing laminoplasty (2). Therefore, it is crucial to ensure minimum soft tissue damage and preservation of the $\mathrm{C} 7-\mathrm{T} 1$ interspinous ligaments during laminoplasty to minimize axial pain and avoid kyphosis (6). A common complication associated with laminectomy is the formation of a post-laminectomy membrane, and laminoplasty may be performed to avoid this. Dural tear is less frequently observed with laminoplasty. In their meta-analysis, Shou et al. found that the incidence of C5 palsy was $5.1 \%$ in patients who had undergone laminoplasty and $11.0 \%$ in patients who underwent laminectomy with fusion (16). The current study was in agreement with this, with the incidence of C5 palsy being $3.9 \%$ in the laminoplasty group and $11.5 \%$ in the laminectomy with fusion group. C5 palsy after laminoplasty is thought to be associated with spinal transposition and C4-C5 intervertebral foramen stenosis. Tsuji et al. limited the laminar opening angle to $53.5^{\circ}$ to prevent spinal slipping (21), while Katsumi et al. performed prophylactic decompression of the C4-C5 intervertebral foramen bilaterally to reduce the incidence of C5 palsy (10).

\section{Limitations}

This study had several limitations. Firstly, the retrospective study design may have led to selection bias, despite the fact that the same inclusion criteria were used for both groups. Secondly, the patient's habits, occupation, and comorbidities were not taken into consideration. Therefore, further prospective studies including larger sample sizes should be carried out in order to achieve more compelling results.

\section{CONCLUSION}

This study showed that both posterior surgical techniques, laminoplasty and laminectomy with fusion, were equally effective in improving neurological functions when treating 
Benek B. et al: Laminoplasty and Laminectomy with Fusion

patients with multilevel cervical spondylotic myelopathy. Laminectomy with fusion should be preferred over laminoplasty in patients with severe axial pain. However, laminectomy with fusion (except for OPLL) should not be the treatment of choice in a mobile spine as it severely restricts neck movements and impairs the health-related quality of life of the patient. In the absence of kyphotic deformity, laminoplasty should be the preffered method for treatment.

\section{ACKNOWLEDGEMENTS}

Preparation for publication of this article is partly supported by Turkish Neurosurgical Society. The authors would like to thank Enago (www.enago.com) for the English language review.

\section{REFERENCES}

1. Baron EM, Young WF: Cervical spondylotic myelopathy. A brief review of its pathophysiology, clinical course and diagnosis. Neurosurgery 60:35-41, 2007

2. Chiba K, Ogawa $Y$, Ishii K, Takaishi H, Nakamura M, Maruiwa $\mathrm{H}$, Matsumoto $\mathrm{M}$, Toyama Y: Long-term results of expansive open-door laminoplasty for cervical myelopathy average 14year follow-up study. Spine (Phila Pa 1976) 31:2998-3005, 2006

3. Du W, Wang L, Shen Y, Zhang Y, Ding W, Ren L: Longterm impacts of different posterior operations on curvature, neurological recovery and axial symptoms for multilevel cervical degenerative myelopathy. Eur Spine J 22:1594-602, 2013

4. Duetzmann S, Cole T, Ratliff JK: Cervical laminoplasty developments and trends, 2003-2013: A systematic review. J Neurosurg Spine 23:24-34, 2015

5. Fehlings MG, Santaguida C, Tetreault L, Arnold P, Barbagallo H, Defino H, Kale S, Zhou Q, Yoon TS, Kopjar P: Laminectomy and fusion versus laminoplasty for the treatment of degenerative cervical myelopathy: Results from the AOSpine North America and International prospective multicenter studies. Spine J 17:102-108, 2017

6. Fehlings MG, Smith JS, Kopjar B, Arnold PM, Yoon ST, Vaccaro AR, Brodke DS, Janssen ME, Chapman JR, Sasso RC, Woodard EJ, Banco RJ, Massicotte EM, Dekutoski MB, Gokaslan ZL, Bono CM, Shaffrey Cl: Perioperative and delayed complications associated with the surgical treatment of cervical spondylotic myelopathy based on 302 patients from the AOSpine North America Cervical Spondylotic Myelopathy Study. J Neurosurg Spine 16:425-432, 2012

7. Harrop JS, Hanna A, Silva MT, Sharan A: Neurological Manifestations of cervical spondylosis: An overview of signs, symptoms, and pathophysiology. Neurosurgery 60(11):14-20, 2007

8. Healy AT, Lubelski D, West JL, Mageswaran P, Colbrunn R, Mroz TE: Biomechanics of open-door laminoplasty with and without preservation of posterior structures. J Neurosurg Spine 24:746-751, 2016

9. Hirabayashi K, Miyakawa J, Satomi K, Maruyama T, Wakano $\mathrm{K}$ : Operative results and postoperative progression of ossification among patients with ossification of cervical posterior longitudinal ligament. Spine 6:354-364, 1981

10. Katsumi K, Yamazaki A, Watanabe K, Ohashi M, Shoji H: Can prophylactic bilateral C4/C5 foraminotomy prevent postoperative C5 palsy after open-door laminoplasty? A prospective study. Spine (Phila Pa 1976) 37:748-754, 2012
11. Lee CK, Shin DA, Yi S, Kim KN, Shin HC, Yoon DH, Ha Y: Correlation between cervical spine sagittal alignment and clinical outcome after cervical laminoplasty for ossification of the posterior longitudinal ligament. J Neurosurg 24:100-107, 2016

12. Manzano GR, Casella G, Wang MY, Vanni S, Levi AD: A prospective, randomized trial comparing expansile cervical laminoplasty and cervical laminectomy and fusion for multilevel cervical myelopathy. Neurosurgery 70:264-277, 2012

13. Nouri A, Tetreault L, Singh A, Karadimas SK, Fehlings MG: Degenerative cervical myelopathy: Epidemiology, genetics, and pathogenesis. Spine (Phila Pa 1976) 40:E675-693, 2015

14. Petraglia A, Srinivasan V, Coriddi M, Gordon MW, Maxwell JT, Silberstein HJ: Cervical laminoplasty as a management option for patients with cervical spondylotic myelopathy: A series of 40 patients. Neurosurgery 67:272-277, 2010

15. Shamji MF, Mohanty C, Massicotte EM, Fehlings MG: The association of cervical spine alignment with neurologic recovery in a prospective cohort of patients with surgical myelopathy: Analysis of a series of 124 cases. World Neurosurg 86:112-119, 2016

16. Shou F, Li Z, Wang H, Yan C, Liu Q, Xiao C: Prevalence of C5 nerve root palsy after cervical decompressive surgery: A meta-analysis. Eur Spine J 24:2724-2734, 2015

17. Singh A, Tetreault L, Casey A, Laing R, Statham P, Fehlings MG: A summary of assessment tools for patients suffering from cervical spondylotic myelopathy: A systematic review on validity, reliability and responsiveness. Eur Spine J 24 Suppl 2:209-228, 2015

18. Stamates MM, Cui MX, Roitberg BZ: Clinical outcomes of cervical laminoplasty: Results at two years. Neurosurgery 80:934-941, 2017

19. Stephens BF, Rhee JM, Neustein TM, Arceo R: Laminoplasty does not lead to worsening axial neck pain in the properly selected patient with cervical myelopathy: A comparison with laminectomy and fusion. Spine (Phila Pa 1976) 42:1844-1850, 2017

20. Su N, Fei Q, Wang B, Li D, Li J, Meng H, Yang Y, Guo A: Longterm outcomes and prognostic analysis of modified opendoor laminoplasty with lateral mass screw fusion in treatment of cervical spondylotic myelopathy. Ther Clin Risk Manag 12:1329-1337, 2016

21. Tsuji T, Matsumoto M, Nakamura M, Ishii K, Fujita N, Chiba K, Watanabe K: Factors associated with postoperative C5 palsy after expansive open-door laminoplasty: Retrospective cohort study using multivariable analysis. Eur Spine J 26:2410-2416, 2017

22. Tumturk A, Kucuk A, Menku A, Koc RK: En bloc cervical laminoplasty with preserving posterior structure and arcocristectomy in cervical spondylotic myelopathy. Turk Neurosurg 27(5):790-796, 2017

23. Wu JC, Ko CC, Yen YS, Huang WC, Chen YC, Liu L, Tu $\mathrm{TH}$, Lo SS, Cheng H: Epidemiology of cervical spondylotic myelopathy and its risk of causing spinal cord injury: A national cohort study. Neurosurg Focus 35:E10, 2013

24. Yoon ST, Hashimoto RE, Raich A, Shaffrey CI, Rhee JM, Riew KD: Outcomes after laminoplasty compared with laminectomy and fusion in patients with cervical myelopathy: A systematic review. Spine (Phila Pa 1976) 38(22 Suppl 1):S183-194, 2013 